\title{
Online hemofiltration in incremental dialysis prescription
}

\author{
Sofia Oliveira Correia, Filipa Santos Silva, Joana Tavares, António Cabrita, José Queirós
}

Nephrology, Centro Hospitalar do Porto, Porto, Portugal

\section{ABSTRACT}

Incremental dialysis is increasingly recognized as a safe and beneficial method of initiating dialysis. Different centers use distinct prescription methods. We discuss the advantages of incremental hemodialysis and the potential benefit of preserving residual renal function as we present our experience. We reviewed the data from 20 incident patients, with a mean follow-up of 9.5 months, who started dialysis with our prescription method, using hemofiltration as the preferred depurative technique. All patients tolerated treatment well; no major complications were reported. Dialysis adequacy targets were achieved. While data are clearly limited, we raise the hypothesis that convective techniques could bring additional benefit in preserving residual renal function in incident patients, and that this strategy should be studied and compared with others.

Keywords: Incremental Hemodialysis, dialysis adequacy, residual renal function, convective techniques, hemofiltration

\section{INTRODUCTION}

\section{What is incremental hemodialysis?}

The concept of incremental hemodialysis (IHD) initially described for peritoneal dialysis (PD) patients, has gained renewed interest. Residual renal function is always considered when prescribing peritoneal dialysis and has the largest number of studies that prove its benefits, including the impact on overall mortality.

IHD is a therapeutic strategy that adapts dialysis dose according to residual renal function (RRF) so that the dialysis dose is individualized. ${ }^{1}$

The literature on incremental schedules is limited, in particular by its observational nature. Discrepancy also exists in the definition of incremental dialysis, which is frequently defined as twice-weekly, without reference to residual function. This approach appears to reduce progressive loss of residual renal function (RRF) in some studies, in both hemodialysis (HD) and PD patients by reducing dialysis intensity. ${ }^{2-4}$

The mechanisms underlying the apparent benefits of initiating incremental dialysis in RRF preservation are not completely understood. According to Thomas et al., initiation of dialysis may lead to the 'deactivation' of stimuli for certain adaptations that occur with progression of loss of renal function - the intact nephron hypothesis in reverse. ${ }^{3}$

It is postulated that the loss of RRF is faster in hemodialysis than in peritoneal dialysis patients due to episodes of intradialytic hypotension and hypovolemia, causing episodic acute renal injury.

In twice a week dialysis, less exposure to the dialysis membrane and extracorporeal circulation may be beneficial. Furthermore, the use of small diameter needles and less frequent puncturing results in less trauma to the vascular access. Reduction of associated costs is also important if there are financially constraints.

On the other hand, higher ultrafiltration rate was associated with worse outcomes, including shorter survival and more rapid loss of $\mathrm{RRF}$, among patients receiving regular HD treatments at a frequency of twice or less per week. ${ }^{5}$ Hwang et al. also found an increased risk of mortality in patients with RRF undergoing twice-weekly HD compared with those with RRF undergoing thrice-weekly HD, despite adequate dialysis dose and fluid control. ${ }^{6}$

Not all authors agree with an incremental dialysis strategy based on decreasing treatment frequency ${ }^{7}$ and there are studies that show no impact in lowering mortality in incident patients. ${ }^{8}$ Vilar et al. reported a better outcome in patients with $\mathrm{KRU} \geq 1 \mathrm{ml} / \mathrm{min} / 1.73 \mathrm{~m} 2$, the study had 650 incident patients managed in an incremental high-flux HD program over a 15 -year period. ${ }^{9}$ Although this may be true, Obi et al. examined the relationship between incremental dialysis regimen and mortality risk and found no difference in all-cause mortality risk. ${ }^{10,11}$ Again, more evidence is needed to prove which strategy is best.

Despite twice weekly being the most known schedule, it is not the only way to prescribe IHD. Next, we discuss the advantages of RRF since one of the main reasons for an incremental approach is the potential for preserving it. 


\section{Why try to preserve RRF?}

A significant number of hemodialysis patients have normal residual urine volume and significant but inadequate residual glomerular filtration rate ( $r G F R)$ at dialysis initiation that often declines during the first weeks or months on dialysis. Though given the well-founded recognition of RRF importance, efforts to preserve it are warranted. ${ }^{12-15}$ There is reliable evidence that it provides a better quality of life and is associated with several benefits, including better survival. ${ }^{16-19}$

The presence of RRF may improve fluid balance and thus provide cardiovascular benefits, reducing left ventricular hypertrophy and ventricular systolic dysfunction. ${ }^{20}$

Kidney function provides benefits to the patient other than solute clearance. Higher RRF was associated with lower levels of inflammatory parameters, lower risk of atherosclerosis, lower abdominal aortic calcification and better nutritional status, better control of anemia and phosphate balance. ${ }^{10,16,20-23}$ The presence of levels of residual urea clearance (KRU) as low as $1 \mathrm{~mL} / \mathrm{min} / 1.73 \mathrm{~m}^{2}$ has been associated with a significantly reduced mortality risk. ${ }^{13}$ In addiction, ADEMEX trial reported that among PD patients, mortality was reduced by $11 \%$ for each $10 \mathrm{l} /$ week/1.73 $\mathrm{m}^{2}$ increment in residual renal creatinine clearance, whereas there was no survival benefit associated with total small solute removal. ${ }^{24}$

\section{Who is eligible for IHD?}

According to several authors, patients candidates for incremental dialysis should meet the following criteria: urine output $>0.5$ liters/ day, interdialytic weight gain $<2.5 \mathrm{~kg}$ (or $<5 \%$ of dry weight) at intervals of 3-4 days, limited or readily manageable cardiovascular or pulmonary symptoms without clinically significant fluid overload, appropriate body size relative to RKF, infrequent or readily manageable hyperkalemia $(K>5.5 \mathrm{mEq} / \mathrm{l})$ and hyperphosphatemia $(P>5.5 \mathrm{mg} / \mathrm{dl})$, good nutritional status without overt hypercatabolic state, appropriate responsiveness to anemia therapy with $\mathrm{Hb}>8 \mathrm{~g} / \mathrm{dl}$, limited or easily manageable comorbid conditions, satisfactory health-related quality of life. ${ }^{25,26}$ Our criteria are described below.

\section{Principles of IHD prescription}

Incremental dialysis is usually prescribed in peritoneal dialysis and the importance of RRF and its preservation in patient prognosis is recognized, as previously mentioned.

The role of incremental dialysis in hemodialysis has received much less attention, conditioned by the intermittent nature of hemodialysis, as discussed below. Most centers do not routinely measure RRF in HD patients and do not account for the presence of RRF in the HD prescription. A very important contribution from the patient is needed, given that interdialytic urine collections are challenging.

Standard prescription, with thrice-weekly HD regimes, 4 hours per session are common, in incident hemodialysis patients. The rate of decline in RRF appears to be greatest during the first 3 months of starting HD and is significantly associated with episodes of intra-dialytic hypotension. ${ }^{27}$ Furthermore, it is likely that intra-dialytic hypotension is not the only factor; there are probably other regulatory mechanisms that mediate the decline in residual renal function. ${ }^{28}$ Additionally, intradialytic imaging studies of the heart and brain suggest that ischemia can occur in the absence of hypotension. ${ }^{29,30}$

Recently there has been renewed interest in this concept, with some observational studies suggesting that an incremental approach to hemodialysis initiation and less frequent dialysis regimes may have benefits including preservation of RRF. 2,31-33

Incremental dialysis uses the concept of adjusting dialysis dose according to RRF so that the dialysis dose is individualized. The basis is to supply adequate dialysis clearance to provide removal of uremic solutes and at the same time individualize a rational control of volemia and then adapting the dose of dialysis as RRF declines. The general principle is to calculate the total amount of urea removal during dialysis and adding this to residual KRU to provide a total composite clearance. $^{1}$

KRU occurs continuously but in hemodialysis, urea clearance is intermittent. Unlike peritoneal dialysis that easily combines peritoneal clearance to RRF since both are continuous, in hemodialysis KRU can't simply be added to dialyzer urea clearance to calculate total Kt/ $\mathrm{V}_{\text {urea, }}$ making incorporation of residual renal function into dosing more difficult.(34) The models on urea kinetics developed over the past few decades, including weekly standard Kt/V $\mathrm{V}_{\text {urea }}$ proposed by Gotch, 35 later refined by Daugirdas et al. ${ }^{36,37}$ and the development of the dialysis "equivalent renal urea clearance" (EKRC) by Casino and Basile 38 provide the framework for combining dialysis and residual urea clearances.

\section{The center prescription perspective}

There are many ways to prescribe incremental dialysis. The Kidney Disease Outcomes Quality Initiative KDOQI guidelines suggested including the contribution of RRF in their target stdKt/ $\mathrm{V}_{\text {urea }}$ of $2.1-2.3,39$ but this is not broadly practiced due to uncertainties about how this can be effectively and safely achieved. The KDOQI guidelines advise measuring RKF by urea clearance (KRU), which has the potential disadvantage of underestimating GFR, but reduces the risk of overestimating GFR and helps facilitate the integration of RKF with dialysis clearance, which by convention is based on urea kinetics. ${ }^{39}$

Based on the advantages and disadvantages of the various strategies previously discussed, we raised the hypothesis of using a prescription method that, to our knowledge, has not yet been described. Next, we explain why.

Patients with significant RRF will receive proportionally less intense dialytic treatment, by delivering a smaller Kt/V in each dialysis 3-times per week, 4-hour dialysis sessions. Lower dialysis dose can be prescribed by using smaller dialyzer surface area, slower blood, slower 
dialysate flows or lesser convective volumes. It can also be achieved with online hemofiltration, a pure convective technique that is less effective in removing small molecules per unit of time. In post-filter online hemofiltration, urea clearance is only achieved by convection. Target dialysis dose is dependent on replacement volume and is usually achieved, although it is not always possible in obese patients where higher blood flow rates are required. Prescription should be dynamically adjusted as RRF declines to intensify solute clearance and optimize fluid management. ${ }^{1,40}$

In acute kidney injury but also in ESRD, we have some evidence that preventing the imbalance of the most efficient techniques but maintaining the advantages of hemodiafiltration (HDF) in hemodynamic balance and medium molecule removal, is hemodynamically more stable. ${ }^{41,42}$ This is also in line with recent guidelines that recommend hemodiafiltration as a treatment for intra-dialytic hypotension refractory to other measures. ${ }^{43}$ It is not known why the convective technique is sometimes hemodynamically more stable, but we can postulate that sodium and water removal are facilitated with convective therapy, since sodium is predominantly removed by convection, allowing a better intradialytic vascular stability, and consequently it has been possible to reduce intradiaIytic complications.

Hemofiltration is a technique that has some resemblance to renal clearance. Therefore, it seems logical to be the first choice of renal replacement therapy. ${ }^{24}$ If this is considered by some for acute kidney injury, why not study the advantages in ESRD?

In this article we aim to describe the methodology adopted at our center for incremental dialysis prescription. We share some preliminary results, the standard clinical and analytical control and intra-dialytic complications.

\section{METHODS}

The methodology adopted in our hemodialysis unit at Centro Hospitalar do Porto is based on different opinions, observations and studies. To date, there is no randomized controlled trial comparing different types of IHD prescription. The approach is always individualized and based on decreased dialytic efficacy in each treatment, using only convective clearance, maintaining the classic 4 hour 3 times/week schedule. We reviewed the data from 20 incident patients who consecutively started in-center $\mathrm{HD}$ and were recruited for this purpose, under the care of the same physician at a single dialysis unit, from January 2017, for a average follow-up period of 9.5 months.

\section{Inclusion criteria}

Dialysis initiation is always based on clinical criteria and not on laboratory parameters. None of our 20 patients started dialysis urgently; they were all outpatients referred from the low clearance clinic.

We consider that all patients who have residual diuresis may be candidates to start an incremental program.
This strategy could not be employed in noncompliant patients whose BP was difficult to control or clinical euvolemia was difficult to achieve.

\section{The prescription}

All patients were treated using biocompatible polysulfone dialyzer membranes, with Fresenius $5008^{\circledR}$ monitor in post-dilution online hemofiltration. Replacement volume was defined according to target dialysis dose.

Ultrapure water (endotoxin $<0,03 \mathrm{UE} / \mathrm{mL}$ and microorganisms $<1 \mathrm{UFC} / 10 \mathrm{~mL}$ ) was used and was regularly monitored according to best European standards. Bicarbonate was used as the buffer, enoxaparin as hypocoagulation and the dialysate temperature used was $35.5^{\circ}$.

\section{Dialysis adequacy and residual renal function}

Dialysis was prescribed using an incremental strategy, increasing the replacement volume according to the target dialysis dose. Transition to hemodiafiltration was made when the dialysis dose was not reached with hemofiltration, or in order to control the analytical parameters such as hemoglobin, phosphorus and potassium. The prescribed dialysis dose was stdKt/N $\mathrm{V}_{\text {urea }} 2,3$.

The weekly residual $\mathrm{Kt} / \mathrm{V}\left(\mathrm{K}_{\mathrm{r}} \mathrm{t} / \mathrm{v}\right)$ was calculated and monitored monthly by collecting 24 -hour urine in the shortest interdialytic interval according to Daugirdas et al. ${ }^{44} \mathrm{Kr} / \mathrm{v}$ was calculated using the following method.

$\mathrm{Kr}$ (liters/week) = urea clearance $(\mathrm{mL} / \mathrm{min}) \mathrm{X} 10.08$ (to convert $\mathrm{mL}$ / $\min$ to liters/week)

Urea clearance $($ in $\mathrm{mL} / \mathrm{min})=[$ [Urine urea $(\mathrm{mg} / \mathrm{dL}) \times$ urine volume (mL/24 hours)] x 24 hours/1440 minutes]/]/plasma urea(mg/dL)

$$
\mathbf{t}=1 \text { week }
$$

V (total body water) was obtained through bioelectric impedance multifrequency (Body Composition Monitor ${ }^{\circledR}$ ) and was considered equal to the urea distribution volume.

The figure developed by Gotch was used to obtain the dose of dialysis required per session (Figure 1). ${ }^{35,45}$ Using this figure, the Krt/V is subtracted from target stdKt/Vurea. This value $(2,3-\mathrm{Krt} / \mathrm{V})$ should then be found in the vertical axis. The intersection of this value and the $3 x$ treatment per week curve gave us the per session required Kt/V (horizontal axis).

$\mathrm{Kt} / \mathrm{V}$ was determined using this method for all patients. The treatment time was 4 hours 3 times per week, for every patient. By providing the parameters: target spKt/ $\mathrm{V}$, urea distribution volume and time, the dialysis monitor calculates the required volume of infusion.

Target volume $=$ desired single pool $\mathrm{kt} / \mathrm{v} \times$ urea distribution volume 


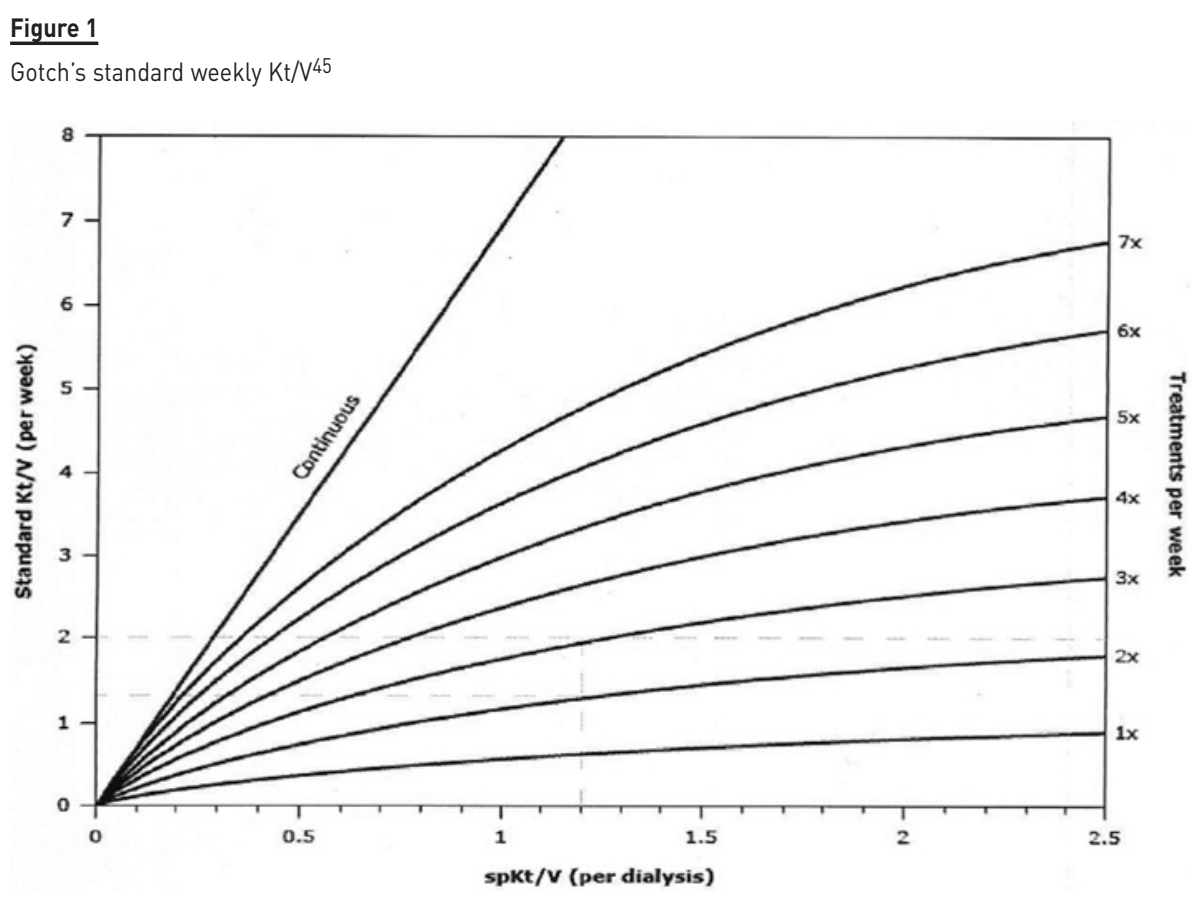

The dialysis dose was evaluated in all sessions through the Online Clearance Monitoring $\left(\mathrm{OCM}^{\circledR}\right)$ module.

\section{Dry weight}

Dry weight is defined by the post-dialytic weight the patient has, while maintaining adequate blood pressure control, with the fewest hypotension symptoms, shortest post dialysis recovery time, fewest hypovolemia-related access thromboses, fewest post dialysis falls and fewest cardiovascular and cerebrovascular events. (adapted from Daugirdas personal communication) Dry weight was attained following clinical evaluation as well as bioimpedance assessment (Body Composition Monitor - BCM, from Fresenius Medical Care ${ }^{\circledR}$ ) that estimates the normohydration weight. Volume status was clinically assessed each session. BCM measurements was performed every 2 months or on demand. The goal was to achieve relative over hydration [(pre-dialysis body weight- normohydration weight)/extra cellular water] of $<15 \%$ in men and $<13 \%$ in woman.

The decrease in dry weight was never greater than 500 grams in each dialysis session. Ultrafiltration rate $<10 \mathrm{ml} / \mathrm{kg} / \mathrm{hour}$ was always respected. All patients were encouraged to restrict salt ingestion, limit interdialytic weight gain (IDWG) to $<4 \%$ of the dry weight and were treated with diuretics to promote diuresis.

\section{Dialysate Sodium prescription}

We use the 2005 National Kidney Foundation Kidney Disease Outcomes Quality Initiative (K/DOQI) clinical practice guidelines definition of intradialytic hypotension: a decrease in systolic BP [SBP] by $\geq 20$ $\mathrm{mm} \mathrm{Hg}$ or a decrease in mean arterial pressure by $\geq 10 \mathrm{~mm} \mathrm{Hg}$ with associated symptoms. ${ }^{46}$

The prescription of dialysate sodium was individualized according to the on-line Clearance Monitor (OCM), data that were determined within the first minutes of hemodialysis treatment. The aim was to prescribe a neutral or negative (- 2) sodium balance (minimum prescribed of $136 \mathrm{mmol} / \mathrm{L}$ ) depending on the blood pressure profile: patients with pre-dialysis blood pressure greater than $160 / 90 \mathrm{mmHg}$ were prescribed a negative balance.

\section{Follow-up considerations}

We tend to start with hemofiltration, provided that the minimum dialysis dose is ensured. The depurative technique was changed to post-filter online hemodiafiltration according on clinical and analytical evolution. If IDWG was high, compliance with low salt diet was reinforced, and diuretic dose adjusted. Nephrotoxins such as radiocontrast dye, nonsteroidal anti-inflammatory drugs, and aminoglycosides were avoided. Monthly analytical follow-up was carried out with residual renal function, dialysis dose based on urea kinetics, blood count, ionogram and phospho-calcium metabolism.

\section{RESULTS}

Patients that initiated hemodialysis at this unit were evaluated and IHD were prescribed if the inclusion criteria were met. Twenty patients were included in this program, starting in January 2017. The 


\section{Table I}

Baseline demographics and clinical characteristics

\begin{tabular}{l|c}
$\mathrm{n}$ & 20 \\
Age, years (median;lQR) & $69.9 ; 19.8$ \\
Male, $\%$ & 75 \\
\hline Body mass index, $\mathrm{kg} / \mathrm{m}^{2}$ (median;IQR) & $25.9 ; 9$ \\
\hline Glomerular filtrate rate $\mathrm{ml} / \mathrm{min} / \mathrm{m} 2$, calculated by MDRD formula & $6.4 ; 2.1$ \\
(median;lQR) & \\
\hline Krt/v, mean $\pm S D$ & $0.78 \pm 0.36$ \\
Type 2 diabetes mellitus & $35 \%$ \\
CVC / AVF & $15 \% / 85 \%$ \\
\hline Etiology of renal failure & $25 \%$ \\
\hline Chronic glomerulonephritis & $30 \%$ \\
CKD of unknown etiology & $10 \%$ \\
ADPRD & $25 \%$ \\
Diabetic nephropathy & $10 \%$ \\
\hline Allograft dysfunction &
\end{tabular}

AVF: arteriovenous fistula; CVC: central venous catheter; CKD: chronic kidney disease; ADPRD: Autosomal dominant polycystic kidney disease

follow-up was $284 \pm 153$ days. Their baseline characteristics at the time of dialysis initiation are shown in Table I.

IHD was well tolerated. There was less than $1 \%$ of intradialytic complications, such as intradialytic hypotension and one episode of atrial fibrillation with rapid ventricular response. There were no further recorded incidents.

The interdialytic weight gain $0.7 \pm 0.79 \mathrm{~kg}$. Eight patients had an interdialytic weight range close to zero. The remaining patients had interdialytic weight gain of $1.2 \mathrm{~kg} \pm 0.66(\min 0.4$, $\max 2.5)$.

Normovolemia control, hemoglobin, calcium, phosphorus and bicarbonate values remained within the intended targets (Table II). During the follow-up there was a hospital stay for sepsis. Mortality rate was $0 \%$.

\section{Table II}

Clinical and analytical characteristics at the end of follow-up

\begin{tabular}{|c|c|c|c|}
\hline Parameters & mean $\pm S D$ & Target & $\%$ on target \\
\hline Hemoglobin, g/dL & $10.6 \pm 0.8$ & $10<\mathrm{Hb}<12$ & $95.0 \%$ \\
\hline Calcium & $8.4 \pm 0.5$ & $\mathrm{Ca}<10.2$ & $100 \%$ \\
\hline Phosphorus & $4.6 \pm 1.0$ & $\mathrm{PO}<5.5$ & $85.0 \%$ \\
\hline PTH & $376.0 \pm 203.5$ & $120<\mathrm{PTH}<600$ & $66.7 \%$ \\
\hline Potassium, mmol/L & $4.8 \pm 0.5$ & & \\
\hline $\mathrm{HCO}^{-}, \mathrm{mmol} / \mathrm{L}$ & $21.0 \pm 1.5$ & $20<\mathrm{HCO}^{-}<24$ & $73.7 \%$ \\
\hline Albumin, g/dL & $3.7 \pm 0.4$ & $>3.5 \mathrm{~g} / \mathrm{dL}$ & $69.0 \%$ \\
\hline $\mathrm{OH} / \mathrm{ECW}(\%)$ & $7.6 \pm 4.5$ & $\mathrm{OH} / \mathrm{ECW}<15 \%$ & $100 \%$ \\
\hline Urine output, ml (mean \pm SD) & $694 \pm 295$ & & \\
\hline $\mathrm{Kr} / \mathrm{v}$ & $0.64 \pm 0.22$ & & \\
\hline Interdialytic Weight gain (mean $\pm S D$ ) & $2.4 \pm 1.8 \mathrm{~kg}$ & & \\
\hline
\end{tabular}

$\mathrm{Krt} / \mathrm{v}$ : weekly residual $\mathrm{Kt} / \mathrm{V} ; \mathrm{OH} / \mathrm{ECW}$ (overhydration volume/extra cellular water)
The following results correspond to the analytical parameters performed at the end of the follow-up.

\section{DISCUSSION}

This methodology, like others described, has many limitations. To begin with, the sample being small, the observational and retrospective methodology and the absence of control population.

Another limitation is the method for calculating clearance. In both stdKt/v and EKRC, renal function (quantified by urea clearance) is considered equal to urea clearance by dialysis. This underestimates the relative contribution of renal function when compared with dialysis. ${ }^{47}$

Dialysis initiation criteria are not always explicit in some observational studies of incremental dialysis. This fact is very relevant, because it is different to compare studies which included incident dialysis patients who started renal replacement therapy before having explicit criteria. Our opinion is that incremental dialysis should only be initiated when the patient has clinical criteria for initiating dialysis and never before.

Many practitioners of incremental dialysis come down in favor of twice per week dialysis. In our opinion, the frequency of dialysis should not be reduced, despite understanding the potential advantages with respect to the vascular access and eventually to the patient's sense of better quality of life. One must consider that the interdialytic weight gain will inevitably be greater, and that with that, a higher rate of ultrafiltration will be needed. In the same way, intradialytic hypotension could be more common.

Intradialytic hypotension (IDH) is the most frequent complication of hemodialysis. Depending on the definitions, IDH is reported to occur between 5 and $30 \% .{ }^{48}$ Hypotension is associated with a number of serious complications and increased mortality, including the often overlooked loss of residual renal function. ${ }^{49}$ The interdialytic weight gain with the corresponding increase in the ultrafiltration/hour is one of the most determining factors for this complication. It is important to realize that even small increases in ultrafiltration rate are associated with increased mortality ${ }^{50}$ and dialysis-induced myocardial damage. ${ }^{30}$

Continuous probing for the optimum dry weight may lead to an increased incidence of intradialytic hypotension ${ }^{51}$ and a rapid decline in RRF in incident hemodialysis patients. ${ }^{52}$ Hypervolemia, on the other hand, does not help to preserve RRF and is also related with increased mortality. ${ }^{53-55}$ Thus, optimizing volume control should be practiced without inducing hypotension-induced organ injury. In our cohort, by prescribing hemofiltration, individualized sodium prescription and respecting the maximum ultrafiltration rate, it was possible to achieve euvolemic weight without complications and preserving residual function.

Similarly, solute imbalance is more abrupt when the frequency is lower and the treatment efficiency is higher. Since disequilibrium syndrome in hemodialysis is responsible for some of the intradialytic complications, incremental dialysis without reducing dialysis frequency was considered. 
Our approach in prescribing incremental dialysis in incident patients with hemofiltration in the classic 4-hour thrice-weekly schedule can overcome many of these issues by providing less efficient treatment per time unit but potentially more physiologically, hemodynamically stable and well tolerated. Conversely, in opposition to the opinion of other authors, ${ }^{40}$ we believe that the initial prescription of renal function replacement technique should be the closest to renal physiology, that currently we believe is hemofiltration: "nature has chosen continuous hemofiltration as the primary methodology of blood purification". 41

Most studies show the advantages of IHD, but the risk of underdialysis does exist and therefore requires adequate RRF control, at least monthly. In our cohort study, higher dialysis dose was achieved by increasing the infusion volume or with the use of hemodiafiltration, in order to achieve the defined targets. The treatment was well tolerated and the complications infrequent, with very few episodes of hypotension (in one patient with autonomic dysfunction). All patients were able to maintain euvolemia according to clinical evaluation and $\mathrm{BCM}^{\circledR}$.

We can speculate that with preservation of RRF, we will improve quality of life, symptoms and overall survival. In our opinion the use of convective techniques, tight clinical and analytical control, dry weight adjustment, patient compliance, correct ultrafiltration rate, diuretic stimulus perpetuated by the existence of urea and other molecules are responsible for preservation of residual renal function.

Measurement of RRF is not standard procedure for HD patients; thus it was not possible to compare our data with a control group. Before the start of this protocol and the availability of convective techniques, at the end of 3 months, most of our patients had lost residual kidney. However, proper comparison with another similar group is essential to assess this strategy.

\section{CONCLUSION}

Efforts to preserve RRF are justified although how best to do so is unclear. Incremental dialysis may be instituted in our population, maintaining the duration and frequency of standard dialysis treatment, through the individualized prescription of the dialysis dose.

In this paper we share the methodology adopted at our unit, in incident patients, taking into account the RRF. We believe this may be a simple way that can be used in hemodialysis units.

Incremental hemodialysis through better RRF preservation could improve patient survival. Thus, it becomes imperative to offer our patients an individualized prescription to preserve RRF. A randomized-control clinical trial enrolling incident patients and comparing incremental HD with the standard prescription and focused on hard outcomes, such as survival and health-related quality of life of patients, is needed. Considering the absence of certainty, one must be cautious in prescribing IHD, closely control residual renal function, and do no harm.

In summary, our findings are limited by the small number of patients and by the short follow-up, but we can verify that patients maintained
RRF and had no significant adverse events throughout the nine months of dialysis. This methodology is practical in day-to-day routine and should be tested in other centers.

We believe that IHD should be considered in all incident patients who start dialysis non urgently and with significant residual diuresis. Our strategy provides some reassurance for the safety of incremental HD.

Given the unacceptably high mortality among incident patients, 56 one should consider every effort in adapting and improving the dialysis prescription. An incremental strategy and the use of convective techniques should be better studied in order to be able to prove some benefit in its use. Future trials are needed to determine whether there is a casual relationship between RRF and patient outcomes among patients receiving incremental doses of dialysis. Furthermore, strategies to protect RRF decline are much-needed.

RRF assessment in daily practice would allow clinicians to monitor and proactively find strategies to protect RRF.

To our knowledge, this is the first method of IHD prescription to be described, without reducing the frequency of dialysis and using only convective techniques.

Disclosure of potential conflicts of interest: none declared

\section{References}

1. Wong J, Vilar E, Davenport A, Farrington K. Incremental haemodialysis. Nephrol Dial Transplant. 2015;30(10):1639-1648.

2. Zhang M, Wang M, Li H, Yu P, Yuan L, Hao C, et al. Association of initial twice-weekly hemodialysis treatment with preservation of residual kidney function in ESRD patients. Am J Nephrol. 2014;40(2):140-150.

3. Golper TA, Mehrotra R. The intact nephron hypothesis in reverse: an argument to support incremental dialysis. Nephrol Dial Transplant. 2015;30(10):1602-1604.

4. Lin Y, Huang J, Wu M, Chu T, Lin S, Chen Y, et al. Comparison of residual renal function in patients undergoing twice-weekly versus three-times-weekly haemodialysis. Nephrology (Carlton). 2009; Feb;14(1):59-64

5. Lee YJ, Okuda Y, Sy J et al. Ultrafiltration rate, residual kidney function, and survival among patients treated with reduced-frequency hemodialysis. Am J Kidney Dis. 2020;75(3):342-350.

6. Hwang HS, Hong YA, Yoon HE, Chang YK, Kim SY, Kim YO, et al. Comparison of clinical outcome between twice-weekly and thrice-weekly hemodialysis in patients with residual kidney function. Med (United States). 2016;95(7):e2767.

7. Vanholder R, Van Biesen $\mathrm{W}$, Lameire $\mathrm{N}$. Is starting hemodialysis on a twice-weekly regimen a valid option? Am J Kidney Dis. 2014;64(2):165-167.

8. Hanson JA, Hulbert-Shearon TE, Ojo AO, Port FK, Wolfe RA, Agodoa LYC, et al. Prescription of twice-weekly hemodialysis in the USA. Am J Nephrol. 1999;19(6):625-633.

9. Vilar E, Wellsted D, Chandna SM, Greenwood RN, Farrington K. Residual renal function improves outcome in incremental haemodialysis despite reduced dialysis dose. Nephrol Dial Transplant. 2009;24(8):2502-2510

10. Wang $M$, Obi Y, Streja $E$, Rhee $C M$, Lau WL, Chen J, et al. Association of parameters of minera bone disorder with mortality in patients on hemodialysis according to level of residual kidney function. Clin J Am Soc Nephrol. 2017;12(7):1118-1127.

11. Obi Y, Streja E, Rhee CM, Ravel V, Amin AN, Cupisti A, et al. Incremental hemodialysis, residual kidney gunction, and mortality risk in incident dialysis patients: a cohort study. Am J Kidney Dis. 2016;68(2):256-265

12. Liu Y, Zou W, Wu J, Liu L, He Q. Comparison between incremental and thrice-weekly hemodialysis: a systematic review and meta-analysis. Nephrology (Carlton). 2019 Apr;24(4):438-444.

13. Vilar E, Wellsted D, Chandna SM, Greenwood RN, Farrington K. Residual renal function improves outcome in incremental haemodialysis despite reduced dialysis dose. Nephrol Dial Transplant. 2009 Aug 1;24(8):2502-2510

14. Basile C, Casino FG, Kalantar-Zadeh K. Is incremental hemodialysis ready to return on the scene? From empiricism to kinetic modelling. J Nephrol. 2017;30(4):521-529.

15. Termorshuizen F, Dekker FW, Van Manen JG, Korevaar JC, Boeschoten EW, Krediet RT. Relative contribution of residual renal function and different measures of adequacy to survival in hemodialysis patients: an analysis of the Netherlands Cooperative Study on the Adequacy of Dialysis (NECOSAD)-2. J Am Soc Nephrol. 2004;15(4):1061-1070. 
16. Shafi T, Jaar BG, Plantinga LC, Fink NE, Sadler JH, Parekh RS, et al. Association of residual urine output with mortality, quality of life, and inflammation in incident hemodialysis patients: The Choices for Healthy Outcomes in Caring for End-Stage Renal Disease (CHOICE) study. Am J Kidney Dis. 2010;56(2):348-358

17. Konings CJAM, Kooman JP, Schonck M, Struijk DG, Gladziwa U, Hoorntje SJ, et al. Fluid status in CAPD patients is related to peritoneal transport and residual renal function: evidence from a longitudinal study. Nephrol Dial Transplant. 2003 Apr;18(4):797-803.

18. Marquez IO, Tambra S, Luo FY, et al. Contribution of residual function to removal of protein-bound solutes in hemodialysis. Clin J Am Soc Nephrol. 2011;6(2):290-296.

19. Pecoits-Filho $R$ et al. Associations between circulating inflammatory markers and residual renal function in CRF patients. Am J Kidney Dis. 2003;41(6):1212-1218.

20. Kong J, Davies M, Mount $P$. The importance of residual kidney function in haemodialysis patients. Nephrology (Carlton). 2018 Dec;23(12):1073-1080.

21. de Sequera P, Corchete E, Bohorquez L, Albalate M, Perez-Garcia R, Alique M, et al. Residual renal function in hemodialysis and inflammation. Ther Apher Dial. 2017;21(6):592-598.

22. Rroji M, Spahia N, Seferi S, Barbullushi M, Spasovski G. Influence of residual renal function in carotid modeling as a marker of early atherosclerosis in dialysis patients. Ther Apher Dial. 2017;21(5):451-458.

23. Chen HC, Chou CY, Jheng JS, Chen IR, Liang CC, Wang SM, et al. Loss of residual renal function is associated with vascular calcification in hemodialysis patients. Ther Apher Dial. 2016;20(1):27-30.

24. Paniagua R, Amato D, Vonesh E, Correa-Rotter R, Ramos A, Moran J, et al. Effects of increased peritoneal clearances on mortality rates in peritoneal dialysis: ADEMEX, a prospective, randomized, controlled trial. J Am Soc Nephrol. 2002 May;13(5):1307-1320.

25. Kalantar-Zadeh K, Unruh M, Zager PG, Kovesdy CP, Bargman JM, Chen J, et al. Twice-weekly and incremental hemodialysis treatment for initiation of kidney replacement therapy. Am J Kidney Dis. 2014;64(2):181-186

26. Obi Y, Eriguchi R, Ou S, -M, Rhee C, M, Kalantar-Zadeh K. What Is Known and Unknown About Twice-Weekly Hemodialysis. Blood Purif 2015;40:298-305.

27. Jansen MAM, Hart AAM, Korevaar JC, Dekker FW, Boeschoten EW, Krediet RT, et al. Predictors of the rate of decline of residual renal function in incident dialysis patients. Kidney Int. 2002;62(3):1046-1053.

28. Chung SH, Heimbürger O, Stenvinkel P, Bergström J, Lindholm B. Association between inflammation and changes in residual renal function and peritoneal transport rate during the first year of dialysis. Nephrol Dial Transplant. 2001 Nov;16(11):2240-5.

29. MacEwen C, Watkinson P, Tarassenko L, Pugh C. Cerebral ischemia during hemodialysis-finding the signal in the noise. Semin Dial. 2018 May;31(3):199-203.

30. McIntyre CW, Burton JO, Selby NM, Leccisotti L, Korsheed S, Baker CSR, et al. Hemodialysis-induced cardiac dysfunction is associated with an acute reduction in global and segmental myocardial blood flow. Clin J Am Soc Nephrol. 2008 Jan;3(1):19-26.

31. Rhee CM, Unruh M, Chen J, Kovesdy CP, Zager P, Kalantar-Zadeh K. Infrequent dialysis: a new paradigm for hemodialysis initiation. Semin Dial. 2013;26(6):720-727.

32. Chandna SM, Farrington K. Reviews: Residual Renal Function: Considerations on its importance and preservation in dialysis patients. Semin Dial. 2004 May 14;17(3):196-201.

33. Tangvoraphonkchai K, Davenport A. Incremental hemodialysis - a European perspective. Semin Dial. 2017 May;30(3):270-276.

34. Daugirdas JT VSJ. Physiologic principles and urea kinetic modeling. In: Handbook of Dialysis. Philadelphia:Wolters Kluwer Health; 2015:34-65.

35. Gotch FA. The current place of urea kinetic modelling with respect to different dialysis modalities. Nephrol Dial Transplant. 1998;13(6):10-14.

36. Daugirdas JT, Depner TA, Greene T, Silisteanu P. Solute-solver: a web-based tool for modeling urea kinetics for a broad range of hemodialysis schedules in multiple patients. Am J Kidney Dis. 2009;54(5):798-809.
37. Daugirdas JT, Depner TA, Greene T, Levin NW, Chertow GM, Rocco M V, et al. Standard Kt / V urea : a method of calculation that includes effects of fluid removal and residual kidney clearance. Kidney Int. 2010;77(7):637-644.

38. Casino FG, Basile C. How to set the stage for a full-fledged clinical trial testing "incremental haemodialysis". Nephrol Dial Transplant. 2017;(January):1-8.

39. National Kidney Foundation. KDOQI clinical practice guideline for hemodialysis adequacy: 2015 update. Am J Kidney Dis. 2015;66(5):884-930.

40. Tangvoraphonkchai K, Davenport A. Increasing haemodialytic clearances as residual renal function declines: an incremental approach. Blood Purif. 2017;44(3):217-226.

41. Ricci Z, Romagnoli S, Ronco C. Acute kidney injury: to dialyse or to filter? Nephrol Dial Transplant. 2020 Jan 1;35(1):44-46.

42. Locatelli F, Altieri P, Andrulli S, Bolasco P, Sau G, Pedrini LA, Basile C, David S, Feriani M, Montagna G, Di lorio BR, Memoli B, Cravero R, Battaglia G, Zoccali C. Hemofiltration and hemodiafiltration reduce intradialytic hypotension in ESRD. J Am Soc Nephrol. 2010 Oct;21(10):1798-807.

43. Ashby D, Borman N, Burton J, Corbett R, Davenport A, Farrington K, et al. Renal association clinical practice guideline on haemodialysis. BMC Nephrology. 2019; 20(397):1-36.

44. Chin Al, Depner TA, Daugirdas JT. Assessing the adequacy of small solute clearance for various dialysis modalities, with inclusion of residual native kidney function. Semin Dial. 2017;30(3):235-240.

45. Bleyer A; Golper T. Incorporating residual kidney function into the dosing of intermittent hemodialysis. Available at https://www.uptodate.com. Accessed Sep 05, 2019

46. K/DOQI Clinical Practice Guidelines for Cardiovascular Disease in Dialysis Patients. Am J Kidney Dis. 2005 Apr;45:16-153.

47. Tattersall J. Residual renal function in incremental dialysis. Clin Kidney J. 2018;11(6):853-856.

48. Chou JA, Kalantar-Zadeh K, Mathew AT. A brief review of intradialytic hypotension with a focus on survival. Semin Dial. 2017 Nov;30(6):473-480.

49. Inrig JK. Beware intradialytic hypotension. Clin J Am Soc Nephrol. 2018 Sep 20;CJN.10150818.

50. Chazot C, Vo-Van C, Lorriaux C, Deleaval P, Mayor B, Hurot J-M, et al. Even a moderate fluid removal rate during individualised haemodialysis session times is associated with decreased patient survival. Blood Purif. 2017;44(2):89-97.

51. Agarwal R, Alborzi P, Satyan S, Light RP. Dry-weight reduction in hypertensive hemodialysis patients (DRIP). Hypertension. 2009 Mar;53(3):500-507.

52. Gunal Al, Kirciman E, Guler M, Yavuzkir M, Celiker H. Should the preservation of residual renal function cost volume overload and its consequence left ventricular hypertrophy in new hemodialysis patients? Ren Fail. 2004 Jan 7;26(4):405-409.

53. Zoccali C, MoissI U, Chazot C, Mallamaci F, Tripepi G, Arkossy O, et al. Chronic fluid overload and mortality in ESRD. J Am Soc Nephrol. 2017 Aug;28(8):2491-2497.

54. McCafferty K, Fan S, Davenport A. Extracellular volume expansion, measured by multifrequency bioimpedance, does not help preserve residual renal function in peritoneal dialysis patients. Kidney Int. 2014 Jan;85(1):151-157.

55. Wizemann V, Wabel P, Chamney P, Zaluska W, Moissl U, Rode C, et al. The mortality risk of overhydration in haemodialysis patients. Nephrol Dial Transplant. 2009;24(5):1574-1579.

56. Bradbury BD, Fissell RB, Albert JM, Anthony MS, Critchlow CW, Pisoni RL, et al. Predictors of early mortality among incident US hemodialysis patients in the dialysis outcomes and practice patterns study (DOPPS). Clin J Am Soc Nephrol. 2007 Jan;2(1):89-99.

\section{Correspondence to:}

Sofia Oliveira Correia, MD

Nephrology, Centro Hospitalar do Porto, Porto, Portugal

E-mail: soacorreia@gmail.com 